\title{
EDITORIAL
}

\section{Renovação e reflexões sobre 2020}

Tatiana Bragança de Azevedo Della Giustina ${ }^{1}$, José Hiran da Silva Gallo ${ }^{1}$, Rui Nunes ${ }^{2}$

1. Conselho Federal de Medicina, Brasília/DF, Brasil. 2. Universidade do Porto, Porto, Portugal.

Enquanto o mundo vive grandes mudanças sociais, comportamentais, econômicas e institucionais em razão da grave pandemia de covid-19, a Revista Bioética chega ao ano de 2021 com novas propostas, novo layout e novas metas de internacionalização. O tema "covid-19" continua a fazer parte do periódico e da vida de todos nós. Anseios, dúvidas e dilemas éticos se tornam cada vez mais evidentes. Os países experimentam seus dramas, cada qual com suas particularidades, embora se assemelhem em muitas situações.

Nos países em que o liberalismo econômico é mais forte, a limitação de liberdades individuais tem sido mais sentida pela população e menos aceita. No entanto, a pandemia aumenta a responsabilidade do Estado sobre a vida das pessoas, especialmente quanto à organização do sistema de saúde pública. Isso se observa no fato de que os melhores resultados têm sido obtidos em países cujo sistema de saúde é universal, conseguindo atingir maior número de cidadãos. Se alguma conclusão é possível extrair desta terrível pandemia é que os países devem reforçar o bem-estar social, sobretudo em matéria de saúde coletiva. É preciso, ademais, que o planeta se una em torno de causas comuns como a da saúde global.

Segundo Rocha ${ }^{1}$, é necessário desenvolver abordagem ética da tensão entre pleitos individuais e coletivos. Cabe ao Estado criar e fazer cumprir medidas legais para deter o avanço da doença, defendendo o bem comum em vez de direitos individuais, conforme apontam Pellegrino e Thomasma ${ }^{2}$. É preciso refletir sobre os recursos alocados e sua utilização de acordo com princípios bioéticos, especialmente a autonomia, a justiça e a beneficência ${ }^{3}$.

A solidariedade e a dignidade de todo ser humano não devem jamais ser esquecidas, ainda que a desigualdade seja ainda mais evidente em situações extremas como a da pandemia. Nesse sentido, como apontam Nohama, Silva e Simão-Silva ${ }^{4}$, o dilema entre saúde e economia revela visão simplista. Quando se trata de saúde pública, a equidade é muito importante. Todos deveriam estar implicados em um mesmo esforço solidário, visto que a saúde é bem individual, mas também coletivo. Uma sociedade mais coesa é uma sociedade mais produtiva ${ }^{5}$.

Em sociedades democráticas, é normal que haja divergências entre interesses e valores. Nem sempre há consenso sobre quais serviços devem ser oferecidos, com quais recursos e para quem. Em meio a essas disputas, neste momento especial vivido pela humanidade, não se pode esquecer das grandes questões da bioética mais prementes do que nunca - abordadas nos artigos desta revista.

A ação política repercute por muito tempo e deve sopesar riscos e benefícios, conduzindo-se pela lucidez e pela compaixão; a ação do médico repercute no futuro imediato, na vida de quem está sendo tratado. A relação médico-paciente, 
porém, tem sofrido grandes mudanças nas últimas décadas. Assim, pensando nessas mudanças, em "Médico como arquiteto da escolha: paternalismo e respeito à autonomia", Lima e Machado recorrem ao conceito de "paternalismo libertário" cunhado por Thaler e Sunstein ${ }^{6}$ para propor que o médico respeite a autonomia do paciente mas o auxilie a tomar a melhor decisão.

Em outro texto, Joaquim Clotet destaca o conceito de "moral craft" - construção que cada grupo social faz na prática, com base em suas vivências -, de Parker ${ }^{7}$, a fim de defender que a moral só pode ser compreendida no contexto real das pessoas.

Já Pereira, Siqueira-Batista e Schramm tratam do processo decisório em internação em unidade de terapia intensiva no contexto de escassez de recursos. Os autores abordam a questão a partir dos referenciais das correntes principialista e utilitarista, concluindo que critérios técnicos e éticos devem ser articulados e que a seleção aleatória seria a mais viável e justa.

Barros e colaboradores, por sua vez, refletem sobre as ciências forenses, conjunto de conhecimentos e técnicas que auxiliam o sistema de segurança pública e a justiça criminal e são regidos por princípios e práticas éticas. $\mathrm{O}$ artigo reflete sobre alguns desses princípios e os vieses envolvidos na atuação dos profissionais das ciências forenses.

Outro artigo, de Lucía Ciccia, questiona a interpretação dimórfica que sustenta a leitura androcêntrica dos corpos feita pela ciência moderna. Mostrando como práticas sociais associadas ao papel de gênero se encaixam nessa leitura, a autora propõe que os correlatos entre genitalidade e diferenças biológicas não se devem necessariamente a processos de diferenciação sexual, mas a estereótipos normativos.

Por sua vez, o artigo de Caicedo-López e colaboradores aborda a perspectiva científica e ética de projetos de pesquisa sobre o uso de elicitores como substitutos de compostos químicos na agricultura. Os autores concluem que, ao que tudo indica, os elicitores respeitam os princípios bioéticos de beneficência, não maleficência, justiça e autonomia, o que torna promissoras as pesquisas que buscam conhecer as interações desses produtos com o meio ambiente.

Outros 14 textos, além desses citados, compõem esta edição, com grande variedade de temas. Em síntese, conclui-se que, apesar da pandemia e de suas tremendas consequências para a saúde de muitas pessoas, a reflexão bioética deve continuar, firme e determinada, de modo a atravessar este momento especial da humanidade projetando um mundo melhor.

Aproveitem, e boa leitura!

\section{Os editores}

\section{Referências}

1. Rocha DM. Pandemia, bioética e distanciamento social: relação entre interesses coletivos e individuais. Aufklärung [Internet]. 2020 [acesso 20 fev 2021];7:37-50. DOI: 10.18012/arf.v7iesp.55342

2. Pellegrino ED, Thomasma DC. Para o bem do paciente: a restauração da beneficência nos cuidados de saúde. São Paulo: Loyola; 2018.

3. Gonçalves L, Dias MC. Discussões bioéticas sobre a alocação de recursos durante a pandemia da covid-19 no Brasil. Diversitates [Internet]. 2020 [acesso 20 fev 2021];12(1):17-36. Disponível: http://bit.ly/37DvTYS

4. Nohama N, Silva JS, Simão-Silva DP. Desafios e conflitos bioéticos da covid-19: contexto da saúde global. Rev. bioét. (Impr.) [Internet]. 2020 [acesso 20 fev 2021];28(4):585-94. DOI: 10.1590/1983-80422020284421 
5. Guimarães C. A importância de um sistema de saúde público e universal no enfrentamento à pandemia [Internet]. Rio de Janeiro: Escola Politécnica de Saúde Joaquim Venâncio; 2020 [acesso 20 fev 2021]. Disponível: http://bit.ly/3sosoO5

6. Thaler RH, Sunstein CR. Nudge: improving decisions about health, wealth and happiness. London: Penguin Books; 2009.

7. Parker M. Ethical problems and genetics practice. Cambridge: Cambridge University Press; 2012. 